\title{
Educação e gestão escolar na América Latina: histórico, desafios e possibilidades
}

\author{
Maria de Lourdes Pinto de Almeida* \\ Cesar Gerónimo Tello**
}

\section{Resumo}

Este artigo pretende pensar a escola como um espaço de tolerância e de respeito, que propicie o desenvolvimento de uma cultura democrática, de maneira que o seu funcionamento estimule a participaçáo de todos na tomada de decisóes. Isso parece ser utópico e não fazer parte da vontade política das lideranças do mundo globalizado e, sobretudo, capitalista. O trabalho escolar realizado na gestão, na maioria das vezes, perde o sentido de espaço de troca, de construção e de relaçáo social, e é encarado apenas como fator de emancipaçáo econômica, moeda de troca, o que é ilusório, pois a remuneração oferecida de acordo com o mercado não atende, há muito tempo, às reais necessidades. Desse modo, objetiva-se discutir a gestáo escolar diante de um contexto histórico na América Latina, ditado por um Estado Neoliberal que não valoriza a Educação Escolar e que entende o trabalho enquanto venda de força produtiva por um salário no final do mês, e não enquanto produção da existência humana.

Palavras-chave: Gestão Escolar na América Latina. Educação e Gestáo. Escola e Gestão na América Latina.

* Doutora em Educação pela Universidade Estadual de Campinas (UNICAMP). Professora do Curso de Pedagogia e da Pós-Graduação em Educação da Universidade do Oeste de Santa Catarina (UNOESC).

** Mestre em Política e Administração da Educação pela Universidade Tres de Febrero (UNTREF), Argentina. Professor em Ciências da Educação das Universidades de La Plata, San Martin e Tres de Febrero (UNTREF), Argentina. 
O objetivo deste artigo é analisar determinadas teorias específicas sobre a "gestão escolar" na realidade latino-americana, tendo a intenção de fazer uma reflexão diante da perspectiva crítica da administração educativa, da qual surge o campo da Gestáo Institucional Escolar. Ao nos referirmos sobre a perspectiva crítica, estamos fazendo uma análise a partir da própria realidade latino-americana, em oposiçâo àquela que denominamos de realidade "utópica" ou ideal.

Atendendo ao processo histórico devemos levar em conta que a administração educacional surgiu nos EUA, segundo alguns autores, há uns 125 anos e se credita a William Harold Payne, superintendente escolar de Michigan, o primeiro livro de administração escolar em 1875, intitulado Chapters on school supervisión (GARDUÑO, 2004)

A categoria temática de gestáo educacional, como campo disciplinar, data dos anos 1970 nos Estados Unidos, de 1970 no Reino Unido e dos 1980 na América Latina. Em cada uma dessas regióes foi se adquirindo diferentes matizes, pois desde a perspectiva clássica anglo-saxônica à gestão educativa das instituiçôes, as quais possuem um forte caráter técnico-instrumental associada ao direcionamento e aos resultados. Nesse contexto, segundo Gentili (2008), a América Latina é a regiâo mais injusta do planeta. Nela, a diferença entre ricos e pobres se multiplica e amplia criando um abismo que parece insuperável para a maior parte da população.

Tudo se globalizou, ou se globaliza, na sociedade passando a exigir um elevado percentual de conhecimento, pois o fenômeno da globalização produziu e produz mudanças radicais no mundo do trabalho.

Nas palavras de Almeida (2003 apud FERREIRA, 2003a, p. 34), essas transformaçôes exigem constantes adaptaçôes: "No mundo globalizado, as indústrias lançam-se numa corrida competitiva em que novas operaçóes surgem, devido à expansão dos mercados e a fusốes das empresas. Verifica-se uma expansão do poder multinacional das indústrias mais poderosas".

No contexto do mundo do trabalho podemos afirmar que a principal característica capitalista é a força de produção ter assumido a forma de mercadoria, onde o trabalhador produz para o capital e não para si, sendo mais um simples objeto de produção. Desse modo, o conhecimento é na contemporaneidade também uma mercadoria da qual o "capital" necessita para sua continuidade. Se até bem pouco tempo a máo de obra era uma importante mercadoria, no mundo globalizado a força de trabalho perde valor e abre-se uma nova categoria chamada sociedade do conhecimento, que nada mais é que a nova mercadoria do capital.

Importante se faz ressaltar que a informação e a inovação são dois fundamentos essenciais, segundo Ferreira (2003a), da sociedade mundializada, onde a circulaçáo maciça de capitais se baseia na informação, na comunicação e no saber. 
Sendo assim, o capital centrado cada vez mais no monopólio de novas tecnologias, o saber presta-se facilmente à globalização que gera cada vez mais o desemprego estrutural, aumento da miséria, da fome e a barbárie social. A crise do desemprego se constitui num dos problemas políticos mais sérios da história humana. Os trabalhadores lutam para manter seu emprego, mesmo à custa de muitas perdas de direitos conquistados historicamente.

Nesse contexto, a questão é como a educação poderá ter um papel decisivo enquanto política pública para novos processos de gestão escolar, que estejam organicamente articuladas com a construçáo de novos processos sociais, voltados para a humanização, a ética e a novos paradigmas quanto à convivência humana?

Ora, "mudanças tão rápidas afetam profundamente o homem, o meio ambiente e as instituiçóes sociais. Estas, especialmente, sofrem tremendo impacto pela aplicaçáo de novas tecnologias que, geralmente, alteram hábitos, valores, tradiçôes que pareciam imutáveis" (Ferreira, 1999, p. 27). Neste contexto, a educação e a formação de profissionais, que são constituintes das relaçóes sociais, reduzem-se ao economicismo do emprego e da empregabilidade, da eficiência e da eficácia, da competitividade e da consequente entropia da formação humana e da cidadania. [...] A gestão da educaçáo, como tomada de decisôes, utilização racional de recursos para a realização de determinados fins (Paro, 2000; Ferreira, 2002), necessita examinar estas determinaçóes à luz dos compromissos com a equidade social e a justiça social. (FERREIRA, 2003a, p. $12)$.

Nessa perspectiva, modelos e métodos de produção como taylorismo, fordismo e, neste terceiro milênio, a ascensão do toyotismo foram implantados com a ideia de concentrar a mão de obra com vistas à dominação e alienação, através de processos fragmentados, intensificando o papel do trabalhador como mero executor, com investimentos e avanços tecnológicos para o controle e acumulaçáo de riquezas por parte do capital.

O taylorismo impóe o desenvolvimento do trabalho através da fiscalização de gerentes e chefias, destruindo o trabalho profissional qualificado, relacionando a ideia de controle à "noção de tarefa", enfatizando o domínio do tempo e o movimento dos trabalhadores.

O fordismo aprofunda os princípios do taylorismo, intensificando o trabalho com um rígido sistema de máquinas, divisão específica do trabalho, produção em grande escala e o controle da vida do trabalhador, representando um modo mais avançado de racionalização capitalista, implementado no processo de trabalho por várias décadas no século XX. 
Enquanto o taylorismo significa o empenho em aplicar os métodos da gerência científica para controlar o trabalho, o fordismo aprofunda essas bases, inovando na busca da adesão dos trabalhadores, mediante ao aumento de salários, e influenciando a "familiarizaçáo" do modo de vida do coletivo dos trabalhadores (Bihr, 1998; Druck, 1999). Ou seja: adaptou os costumes da sociedade às necessidades do "novo método de trabalho", com a racionalização do trabalho, invadindo a vida íntima dos operários, lançando a mão do controle de sua "moralidade". (ALVES, 2006, p. 48).

O modelo de produção japonês, o toyotismo, trouxe uma perspectiva e um discurso de um trabalho mais flexível nos setores de produção, enfatizando o trabalho em equipe, porém a reconfiguração deste modelo, aliado ao local e mercado de trabalho, deu-se muito mais a favor do empresário do que dos trabalhadores.

No que diz respeito à questáo de qualificação, o toyotismo toma como base na sua estrutura a flexibilização dos trabalhadores. O objetivo é transformar os trabalhadores em profissionais polivalentes, "trabalhadores multifuncionais". No taylorismo-fordismo, a preocupação central era destruir o saber do trabalhador pela via de especializaçáo; método japonês trabalha segundo o princípio da desespecializaçáo, polivalência operária e intensificação do trabalho (Coriat, 1994). O trabalho é desenvolvido segundo o princípio do "tempo partilhado", isto é, o tempo de trabalho é determinado pela eficácia do trabalhador individual em seu posto de trabalho. (ALVES, 2006, p. 48).

Devemos considerar, como bem disse Casassus (2000) em seus estudos, que a gestão educacional não é somente pragmática como poderíamos pensar, pois há uma dimensão política inscrita em sua prática, assim como a gestão escolar está imbricada nas políticas educativas que saem do Estado como políticas públicas. E é exatamente aqui que se dividem as águas, tanto a nível macro como micropolítico da gestáo educativa.

Nesse contexto, as indagaçóes são inúmeras e constantes a professores, gestores, enfim, a sociedade na sua totalidade. Entender a crise que sacode a escola nesse início de século XXI remete-nos a entender suas fontes históricas, bem como os caminhos ou as tendências para o cenário educacional que nos impulsiona ao agir consciente e coletivo e a sairmos do imobilismo nebuloso que nos arrasta para a desesperança, o individualismo e, lamentavelmente, a descompromissos éticos para com a educação. 
Desse modo, as práticas educacionais se tornam ações isoladas, pois não possibilitam o diálogo dos sujeitos envolvidos. Reunióes pedagógicas e conselhos de classes sáo exemplos dessa crise, onde muito se fala e nada se diz.

A escola acabou perdendo sua base de cientificidade, de solidez fundamentada teoricamente e capaz de emancipar os sujeitos como interlocutores de um processo social efetivo para as necessárias e urgentes mudanças sociais. Compreendemos que a escola, nesse contexto, náo consegue romper com essa lógica de apenas ir "tocando em frente".

Destacamos que a globalização imposta pelos países ricos só aprofundou, desde o início dos anos oitenta o abismo entre ricos e pobres.

A ofensiva neoliberal ou dos governos liberais impóe, a partir do Consenso de Washington, em 1989, políticas de ação de dominação das elites financeiras internacionais aos países pobres.

Essa realidade, portanto, fragiliza, desestabiliza e muda radicalmente o contexto da política econômica contemporânea, cujos maiores efeitos são sobre as políticas educacionais no cenário do século XXI.

Sendo assim, segundo Emir Sader (2005 Apud MÉSZÁROS, 2005, p. 16):

No reino do capital, a educação é, ela mesma, uma mercadoria. Daí a crise do sistema público de ensino, pressionado pelas demandas do capital e pelo esmagamento dos cortes de recursos dos orçamentos públicos. Talvez nada exemplifique melhor o universo instaurado pelo neoliberalismo, em que "tudo se vende, tudo se compra, tudo tem preço”, do que mercantilização da educação. Uma sociedade que impede a emancipação só pode transformar os espaços educacionais em shopping centers, funcionais à lógica do consumo e do lucro.

E, nos últimos anos, tanto nos países centrais como naqueles que não se consideram como tais têm tendido a aceitar uma "nova ortodoxia" de políticas educativas (BALL, 2001), que aponta para reforçar as conexôes entre educaçáo, emprego e o melhoramento da economia nacional; e tudo isso complicou os pressupostos educativos, estabelecendo controles centrais mais diretos sobre o currículo e a avaliação, buscando mecanismos de descentralização das escolas, guiados por ideologias de mercado e gerencialismo.

Assim, afirma Martín Carnoy (2002, p. 4), ao referir-se à experiência das reformas educativas na América Latina, sobre o controle dos recursos financeiros que exercem os ministérios nacionais aos governos locais, distritos e escolas, a tal ponto que "[...] os governos fomentaram a educação privada como uma forma de reduzir o gasto público na educaçáo”. 
Nesse sentido, ao referirmos as políticas educativas devemos considerar que, em 1994, a Secretaria da Organização Mundial do Comércio (OMC) constituiu um grupo de trabalho encarregado de estudar as perspectivas de una mayor liberalización da educação. Seu informe destaca o rápido desenvolvimento da aprendizagem a distância e a multiplicação da colaboração entre instituições de educação e empresas.

O ressurgimento da Teoria do Capital Humano tem um custo muito alto para os setores menos favorecidos: a política de desregulação estatal segue gerando um profundo alargamento entre aqueles que estariam dentro e fora desse novo cenário social. Mas havia uma convicção explícita desde 1990 que alguns setores da tecnocracia nacional e regional institucional teriam novos elementos estratégicos, tais como os mencionados, que fariam uma mudança educacional mais viável (BLASCO; RODRÍGUEZ, 2003)

De acordo com Maria Eugênia Bello (2001), estudos sobre a sociedade latinoamericana concordam em caracterizar o impacto da globalização, com fatores específicos, tais como: a frágil estabilidade política, os níveis de integração e de coesão social muito baixa, os altos níveis de pobreza e frustração, inconsistências entre ambiçáo e de viabilidade, as estruturas sociais compostas de elites com formação ampla, que acumulam a maioria dos recursos, e uma grande massa com diferentes graus de falta de acesso à educação. E, nesse sentido, a autora afirma que:

De allí, la insistencia, desde los diferentes organismos nacionales y sobre todo regionales e internacionales, de acoger aquellos enfoques y políticas económicas que favorezcan el crecimiento, en un contexto de equidad y justicia social, en el que las políticas económicas y las sociales interactúen en favor de los habitantes de estas regiones. Abundan las referencias al hecho de que en América Latina la desigualdad en la distribución del ingreso es significativamente más notoria que en otras regiones del mundo con similares niveles de desarrollo. La pobreza aumentó durante toda la década de los ochenta y el número de personas que viven en condiciones de pobreza siguió y sigue aumentando. (BELLO., 2001, p. 14).

Supondo que as condiçóes materiais de vida dos alunos são um fator-chave no seu sucesso educativo, não podemos deixar de lado as estratégias sociais para melhorar essas condiçôes, a fim de enfrentar adequadamente o campo educacional. Esta foi a premissa da força-neoliberal de globalização através de grandes organizaçôes internacionais para definir as questôes políticas de educação da América Latina.

O impacto dos organismos internacionais na definição das políticas educativas, por exemplo, está posto tanto na sua capacidade de mobilizar especialistas, na 
convocação de líderes, conselheiros, e na tentativa de legitimar e distribuir as políticas atuais, como o financiamento de programas e projetos específicos. Não é só o poder econômico, mas também um poder que de certo modo alega experiência (CORAGGIO, 1994).

Essa perspectiva começa a enfatizar as políticas de educação na modernização da educação, identificados com privatizaçôes e redução do papel do Estado (BLASCO; RODRÍGUEZ, 2003). A modernização educacional converteu-se em um bem desejável por meio das reformas, e estas estiveram vinculadas à crise econômica e global, à crise da legitimidade do Estado (GINSBURG, 1991; GINSBURG et al., 1990).

Recuperarmos a essência da educação pública como espaço de inclusão social Acreditando na história como possibilidade e não como determinismos. O empobrecimento da grande maioria da população é uma construção humana histórica e não uma determinação divina.

$\mathrm{Na}$ atualidade, o modelo neoliberal exibe uma nova humanidade deshumanizada (GARRETÓN, 1999; SVAMPA, 2005) e injusta, que cremos e assume características particulares no contexto latino-americano, uma realidade tâo particular como a de outras regióes, mais identificada por fatores e condicionamentos próprios. Isso nos compromete náo somente a pensar e a fazer uma lista dos problemas que os países centrais não têm, mas sim a assumir a responsabilidade sobre os problemas latino-americanos que exigem uma abordagem singular. É aqui onde a sensibilidade intelectual e a capacidade de estar atento aos problemas emergentes jogam um papel determinante no momento de pensar, questionar e intervir sobre as experiências educativas.

Existe a necessidade de estabelecer modos de intervenção tanto na realidade educativa própria, ou seja, não copiado, e às vezes reativa e rebelde, como nas estratégias profundamente enraizadas em nossa maneira de ver os problemas e necessidades, desde o sentimento de nossa própria terra, a riqueza das culturas e tradiçóes, situaçóes de desigualdades sociais marcadas pelos setores de exploração neocoloniais, a profunda assimetria na distribuição de recursos, a insegurança no trabalho e a restrição dos benefícios tecnológicos, são os principais deles.

A natureza hegemônica do modelo neoliberal exige um olhar crítico a partir do contexto latino-americano, principalmente sobre a alta incidência de perspectivas teóricas cunhadas em países centrais e ideologias legitimando seus efeitos e perspectivas epistemológicas. Portanto, a gestáo educacional deve ser concebida a partir da realidade.

Destacamos, nesse cenário, a atuação e intervenção do Banco Mundial na elaboração e implantação das políticas públicas educacionais na América Latina para 
atender os interesses do "capital internacional". Desse modo, não nos enganemos, as políticas públicas estáo postas para atender aos interesses de ajustes que o mundo globalizado impóe aos mais pobres e a escola é tributária desse projeto. Segundo Monvelade e Abádia (2000, p. 75):

De maneira crescente o Banco Mundial, desde os anos sessenta, tem participado de forma sistemática e direta nas decisóes, com capacidade para intervir e formular políticas educacionais para a América Latina. Tem sido expressiva a sua presença no campo educacional, mediante formulaçôes de políticas e estratégias traduzidos em projeto, programas e reformas que os Estados capitalistas latino-americanos deveráo incorporar para fazer jus à aprovaçáo dos empréstimos externos. Utilizando-se do artifício de cooperação e de ajuda técnico-financeira o propósito de desqualificar o outro, prática recorrente que se constitui em uma ferramenta de intervençáo e de dominação, confinando os países devedores, os governos, as instituiçóes e a maioria da população a uma posiçáo marginal e de subserviência.

No entanto, todo este histórico educacional é complexo e marcado por profundas incertezas em relação às condiçóes de vida digna na busca da realizaçáo humana em sua trajetória. Tais complexidades deflagram uma profunda crise da razão predominante nas sociedades ocidentais, pois, segundo Ferreira (2003b, p. 29), “[...] hoje o ser humano está perdido à deriva do que fazer e como se realizar". Os efeitos catastróficos desse processo evidenciam, principalmente, o esvaziamento do Estado como garantia de atendimento aos direitos básicos do ser humano, particularmente, a educação pública.

Devemos considerar que estamos testemunhando um momento sem precedentes na história da educaçáo em relação à escola. Esta é a crise da escola estrutural gestada na e para a modernidade, tấo única como os tempos e as variáveis sócio-políticas em que ocorrem. Poderíamos citar, como características da crise atual, três razōes fundamentais: desinstitucionalização, transicionalidade cultural e fragmentação social. Essas questôes estão gerando deslocamento e incompatibilidade, considerando que a escola foi concebida em um período particular da história para atender demandas específicas da sociedade e atualmente isso não se efetiva. A partir desta perspectiva, René Kaes (1996, p. 29) abordou a questão da direção da escola:

É sempre um momento crítico na história quando eles surgem e insistem que a questáo da transmissáo e da necessidade de ser uma representação do mesmo: na época, entre as geraçóes, 
introduzir elementos de incerteza sobre as ligaçóes, os valores, conhecimento para passar para os beneficiários da herança.

No entanto, a perda de sentido, da identidade da Escola, é uma perda que tem um sentido capitalista? Porque a escola surge em um contexto histórico capitalista.

Aprofundam-se os baixos índices na aprendizagem da América Latina, ou seja, nossos "modelos educacionais" estão em crise, não respondem às complexidades sociais de nossos tempos. Em tempos de globalização para poucos, profundas inquietaçôes nos impulsionam a assumir um compromisso ético quanto ao papel da educação que, deve possibilitar, permitir e facilitar respostas às provocaçôes da própria existência.

O enfoque às discussōes sobre a gestão na educação é recente e aparecem como inovaçôes ou superação de conceitos limitadores de administração, trazendo para a gestáo a importância do elemento humano como articulador, possibilitando, assim, as condições para a melhoria na qualidade de ensino e a transformação da própria identidade da educaçáo na América Latina e de escolas que apresentam ainda problemas quanto às lideranças competentes. Há bem pouco tempo, dirigir uma escola era uma tarefa rotineira. Cabia ao diretor zelar pelo bom funcionamento da escola, centralizando em si todas as decisóes, e administrar com competência os eventuais imprevistos.

No final da década de 90, do século XX, e neste início de século XXI, essa situação mudou muito. As grandes e contínuas transformaçôes sociais, científicas e tecnológicas passaram a exigir um novo perfil de dirigente, com formaçáo e conhecimentos específicos para o cargo e a função de diretor-gestor para a superação das dificuldades cotidianas. Conforme Ferreira (2003b. p. 19), "A questão real que se coloca é sobre o papel da gestão democrática da educação como prática política responsável e coerente".

Como nos afirma GRAMSCI (1978, p. 22), "Como é possível pensar o presente, e um presente bem determinado, com um pensamento elaborado por problemas do passado, muitas vezes bem remoto e ultrapassado? Se tal acontece significa que somos anacronistas em nosso próprio tempo".

Verifica-se que numa sociedade de mercado, numa lógica de globalização, façamos dos conhecimentos e saberes uma práxis voltada à construção de outro mundo. Portanto, a escola tem um papel fundamental que não é apenas reproduzir conhecimentos estáticos, mas tornar-se espaço de discussão, reflexão e análise do contexto mundial, articulando a escola com os interesses populares. Segundo Saviani (1997, p. 81), “[...] trata-se da apropriação das camadas populares das ferramentas culturais necessárias à luta social que travam diuturnamente para se libertar das condiçôes de exploração em que vivem”. 
Como foi sugerido, no parágrafo anterior, não se trata de gestão educativa, mas sim, de gestionar para fundar. Isto é, trabalhar em condiçôes que produzam ao menos rajadas de sentido: um devir. A sua origem se deu em 1980 e é acusada de um clima político forte, manifestado pela quebra de um modelo de Estado de serviços públicos, o que levou a um outro sistema em que o Estado tendeu a reduzir o seu papel para a definiçấo de objetivos. Não se tem ainda uma conceituação sobre gestão educacional da escola, deixando mais espaço para planejamento interno e regulamentaçáo, para atingir estes objetivos. Essa reduçáo de planejadores e poderes administrativos do Estado se traduz na esfera educacional, fazendo com que as próprias escolas usem uma pseudo autonomia como um fator de motivação a possibilidade de autogestão, produzindo o que Contreras (1999) chama de autonomia por decreto. Autonomia (de serviços públicos e cidadãos), a descentralização e desregulamentaçáo do poder do Estado para a sociedade são, ao que parece, termos abstratos designando seus mais altos valores e aspiraçôes. Claramente, a retórica que acompanha essas mudanças, pelo patrocinador, é o que representa um ganho de liberdade pessoal e social, a recuperação da iniciativa e ação livre (CONTRERAS, 1999).

Por essas razôes, manifesta-se claramente que a categoria de gestáo educativa está carregada de sentido e ideologias, desde a gestão institucional: como realidade estranha e, assim como a perspectiva crítica, como parte de nossa própria realidade posta em nosso concreto pensado. Dessa forma, a escola passa a cumprir o papel de educar "os pobres" para melhor servir aos que historicamente pensavam e pensam a sociedade.

Nesse sentido, pensar a educação no contexto da globalização é pensar em gestáo de processos na educaçáo, no papel da gestáo educacional. Bem ou mal, cabe à gestấo da educaçáo não somente tomar consciência e fazer críticas individuais, mas buscar uma responsabilidade conjunta para além das consciências individuais onde de fato todos sejam sujeitos do processo, isto é, da práxis coerente. Isso implica em profundas mudanças e superação nas relaçôes entre os sujeitos que ainda são marcadas pelo autoritarismo e por uma fachada dialógica que não passa, muitas vezes, de falsa generosidade.

Paradoxalmente, essa realidade provoca a estagnação dos avanços e rupturas, pois a escola apresenta dificuldades para responder a inúmeras complexidades. A prática escolar fragmentada e desarticulada apenas reproduz com maior ou menor excelência um modelo de escola que não responde à contemporaneidade. Importante ressaltar o que Enguita (apud Ferreira, 2003b) nos afirma de que os alunos passam a depender cada vez menos somente do professor, mas sim de um conjunto de organização e de sua capacidade de atuar no conjunto. Desse modo, a organização escolar, para sobreviver, 
vê-se obrigada a atuar como um sistema aberto. A escola funciona na maioria das vezes nas palavras de Enguita (apud Ferreira, 2003b, p. 98):

É um lugar comum que numerosos centros são pouco mais, ou são nada mais, que uma soma de mestres professores ou professores, ou seja, que funcionam como uma coleção de salas e aulas superpostas, sem relação alguma entre si; em suma, como um agregado ou, para dizê-lo mais graficamente, como um simples amontoado de indivíduos sem relação entre si.

Esse é um caminho árduo, pois o contexto da globalização individualiza cada vez mais o ser humano e nosso século é marcado por muitas dúvidas e poucas certezas.

Retomando o foco de nossa discussão quanto ao perfil da gestáo numa cultura globalizada, cabe-nos situar os contextos educacionais construídos ora em modelos extremamente autoritários, tecnicistas e fragmentados, ora perde-se em práticas espontaneístas de gestáo. E, neste início de terceiro milênio, na contemporaneidade, quem manda na escola? Os professores, os alunos, os funcionários, a diretora ou o diretor, a secretaria da educação, o prefeito, governo estadual ou federal? Quem manda de fato na educação no contexto da globalização?

Pelas novas leis de educação latino-americana na década de 1990 (ARGENTINA, 1993; BOLIVIA, 1994; BRASIL, 1996; CHILE, 1990; MÉXICO, 1993), e que tem se transformado na década de 2000 (ARGENTINA, 2006; BOLIVIA, 2010; BRASIL, 2009; CHILE, 2003; ECUADOR, 2011; MÉXICO, 2004; PERÚ, 2003; URUGUAY, 2008), em sua maioria, não chega a modificar a realidade do continente latino-americano. No entanto, a comunidade educacional trabalha genericamente esses desafios.

Nossa atuação no mundo e com o mundo deve constituir-se numa atividade transformadora da realidade social. A sociedade do conhecimento exige-nos outra escola para um mundo de constantes mudanças. Há necessidades de repensar os "modelos" que não respondem mais ao contexto da sociedade contemporânea. De acordo com Lück (2006, p. 29-30):

As deficiências em gestão ocorrem por falta de referencial, organização e orientaçóes adequadas para nortear a atuação educacional com a devida competência. Desperdiçam-se recursos, tempo e, o que é mais grave, talento humano, com sérias repercussóes sociais, quando se entende que os problemas de ensino são apenas de natureza didática, e não de gestão pedagógica, a serem resolvidos envolvendo, de forma dissociada, novas técnicas e exercícios de ensino, mais materiais escolares, capacitação de professores, sem esforço em articular e 
coordenar a proposta pedagógica e processos correspondentes, dinamizando-os de forma criativa, sistemática e contínua.

Constatamos que modelos de gestão fechados em si mesmo reforçam somente as injustiças sociais de toda ordem. Entretanto, as instituiçôes educacionais, de um modo geral, ainda não tomaram consciência da necessidade de criarem uma gestão ágil, dinâmica e comunicativa para o empreendimento de seu plano de ação. O principal desafio que se impóe hoje à gestão da escola é redefinir a cultura organizacional instaurada. Sem essa mudança, outras inovaçôes correm o risco de tornarem-se ineficazes.

Desse modo, evidencia-se hoje nos processos escolares a importância da gestão como articulação dos processos, com capacidade para o diálogo. Não cabem mais na educação contemporânea "discussôes encasteladas" ou "reflexões solitárias", que se perdem em si mesmas, ou no máximo alcançam algumas "reformazinhas e acomodaçôes", sem, no entanto, provocar as mudanças emergenciais na sociedade humanizada. Se isso não ocorrer, a agravante desesperança e imobilismo, ou "verdades absolutistas" não possibilitarão avanços para além de constataçôes e modernismos. Sendo assim, que possamos, diante das complexidades, ser sensíveis, solidários e comprometidos politicamente com a construção de um mundo melhor, e que a vida das nossas crianças, adolescentes, jovens e adultos das escolas públicas não nos sejam indiferentes.

Refletir sobre o papel da gestão para o século XXI, é criar condiçôes para a autoconsciência que só se dará pelo conhecimento que nos exige uma outra qualidade e quantidade para um novo perfil de gestão. A educação continuada da gestáo não pode mais ficar à mercê dos discursos no contexto da chamada sociedade do conhecimento.

O desenvolvimento da pesquisa aponta aspectos importantes relativos à forma de os gestores verem, entenderem e avaliarem a atual situação de sua prática no cotidiano escolar, visando sua atuação num período histórico caracterizado por profundas mudanças. É fato que as situaçôes no mundo do trabalho, no mundo social, cultural e educacional têm demandado novas posturas por parte dos gestores e de seu corpo docente, no entanto, sabemos que, tanto as estruturas burocráticas como as humanas, reagem de forma lenta às implicaçóes das mudanças. Conhecer o pensamento sobre a formação da gestão é poder prognosticar efetivas mudanças na estruturação da educação permanente, bem como as possibilidades de mudanças na formação dos futuros gestores.

Entretanto, podemos afirmar que a questão da gestão poderá ter modificaçôes quantitativas e qualitativas e que a implementação dessas modificaçóes depende, em grande parte, do entendimento que os gestores têm de seu papel. Sabemos que as açóes 
que podem e devem ocorrer no seio das instituiçôes só terão repercussão se a escola, e seus agentes, modificarem o olhar para o seu papel quanto à formação do aluno e, por conseguinte, modificar a organização e estruturaçáo das atividades curriculares em seu Projeto Pedagógico.

Podemos dizer que o debate sobre a gestáo procura buscar superar, através de uma nova cultura de formação do gestor, a falta de referencial teórico em aspectos fundamentais da sociedade, da civilização e da cultura. Podemos dizer ainda que as perspectivas atuais estão mais abrangentes e englobam aspectos de totalidade na formação dos gestores. Elementos importantes no tempo são extremamente necessários: integração dos conhecimentos; compromisso ético; atualização contínua do conhecimento; consideraçáo dos aspectos sociais no desenvolvimento das pesquisas e das atividades profissionais; e comportamento investigativo.

A escola, como instituição na sua longa existência, tem sido marcada por discussôes que refletem, fundamentalmente, posiçôes divergentes quanto à sua finalidade e função, o que leva, necessariamente, a diferentes posicionamentos em relação à sua organização. Esses posicionamentos, que marcam diferenciaçôes na forma de planejá-la, têm explicitado funçóes das mais díspares, que vão desde entendê-la como uma instituição essencialmente burocrática ou como espaço da expressão da construção de outras possibilidades.

Todas essas tensões e contradições mostram a importância da discussão das questôes relativas à gestão e revelam que essa tem sido uma tarefa de grandes proporçóes, uma vez que a educação é permeada pela complexidade da sociedade moderna.

Por serem os gestores os agentes da ação escolar, o conhecimento sobre as concepçôes que têm a respeito da finalidade da sua formação, do papel da instituição escolar, torna-se de grande importância. Vivendo em um tempo de grandes mudanças sociais e culturais, os gestores demonstram sua inquietaçáo de que há a necessidade de alteraçóes na sua formaçáo. No entanto, encontram-se confusos quanto à direção que estas devem tomar. Desse modo, conhecer e explicitar essas alteraçóes é contribuir de forma significativa para uma melhor e mais coerente ação pedagógica.

Concordando com Schön (1992), consideramos que a gestão é uma reflexão, em oposição a um conceito que a valida como tecnicismo-instrumental. Para o autor, a gestão, enquanto uma reflexão, é uma ação que requer uma função crítica e que dá lugar a uma experiência vivenciada em um contexto: "Ideamos y probamos nuevas acciones que intentan explorar los fenómenos recién observados, verificamos nuestra comprensión provisional de los mismos o afirmamos los pasos que hemos seguido para que las cosas vayan mejor” (SCHÖN, 1992, p. 38). 
O conceito de gestão educativa que é pregado pelo pensamento neoliberal, possui dois pilares centrais: a racionalidade econômica e a da moral vinculada a si mesmo (it yourself). A racionalidade econômica refere-se a um tipo de inteligibilidade do mundo, que nos diz que a economia é um princípio estruturador da vida. O sujeito nesta racionalidade - é um sujeito de interesses, desprendido do sujeito da razão. Tratase de um sujeito irredutível à lei e submetido ao cálculo custo-benefício. Dessa forma se constitui no sujeito de cálculo: impacto e benefício seriam os objetivos centrais da gestão educativa. Este sujeito de interesses está vinculado ao seu modo de operar a modalidade de gestionar. É exatamente aqui que os mecanismos econômicos invadem a realidade da escola, reconhecendo que existe um "usuário" que não necessita do Estado.

Para tanto, poderíamos dizer que não é inexplicável que determinados termos circulem atualmente ao redor dos discursos: management, qualidade total, escola inteligente, impacto, benefício, reengenharia, normas ISO. Uma grande dificuldade que se implantou neste discurso esteve inerentemente vinculada à questão disciplinar, com um enfoque disciplinar neoliberal, uma epistemologia neoliberal. Para Casassus (2000), um problema que acontece na América Latina tem a ver com a ausência da dimensão educacional da gestão educacional.

Assim, a gestão educativa converteu-se, simplesmente, em um espaço de aplicação de princípios gerais da gestão, quando a realidade supunha que disciplinarmente ambos os campos deviam se convergir para abordar a problemática, e o que se dizia era que isso náo seria pertinente ou não, sendo parte de uma incapacidade epistemológica, já que se articula claramente a lógica neoliberal da condução da educação. Na teoría da gestión, os processos que levam à produção do produto se formalizam em função. Essas funçóes são basicamente as de planejamento estratégico, gestão financeira, gestão de recursos humanos e de vínculos com os usuários.

Essas funçôes têm sido aplicadas à gestão educativa e de termos, que mencionamos anteriormente como necessários ao momento de se pensar a economia de produção. E a escola como fica? Em uma economia de produção, os critérios são chaves para se pensar processos de ressignificaçấo de recursos, determinantes com precisão de produto, medir o rendimento do sistema, determinar o âmbito e os níveis de qualidade, referi-los a estandartes e, a partir desse elo, alinhar processos para melhorar a produtividade (eficiência) e o produto (eficácia). Estamos fazendo referência à escola neste contexto caótico neoliberal, onde a escola faz papel de uma empresa?

Surgiu um outro conceito no contexto educacional sobre a gestáo que significa liderança, organização, gestão, que é adotado pelo discurso educacional, a fim de repensar estratégias de otimização de serviços. Como qualquer agência do mercado, a escola agora é uma prestadora de serviço e tão simplesmente de serviço, tornando a instituição de educação uma mera organização. 
Como podemos observar, a lente através da qual a realidade é observada, no que se refere à gestão educacional, muitas vezes, é determinada pelo neoliberalismo que determina o processo pedagógico da escola. Se o que conta é a nova demanda do mercado, apenas tentam moldar a escola para combinar com o imperativo emergente. A escola passa a ser uma instituição gerenciada pelo mercado e o gestor, um mero agente de integraçáo da Escola com o Mercado Capitalista.

Agora, vamos tomar um outro caminho, um divisor de águas, como costuma-se dizer na Argentina, optaremos por analisar os efeitos que produziu o neoliberalismo na sociedade, a subjetividade e, por fim, a gestáo educativa, tentando desnudar os problemas produzidos e potenciar as possibilidades subjetivas desta discussão científica.

No entanto, decidiu-se tomar outro caminho, pois vamos optar por analisar os efeitos produzidos pelo neoliberalismo na subjetividade da sociedade, e, portanto, a gestáo educacional, tentando desembaraçar os problemas causados e aumentar as oportunidades de inclusão dos menos favorecidos economicamente. Mas isto náo ocorre, pois na maioria das vezes, a escola com as políticas neoliberais de educação perdeu sua identidade e o gestor educacional também.

Desse modo, queremos aqui apresentar alguns dos postulados próprios da gestão educativa na realidade latino-americana, mas antes devemos considerar, como mencionamos em linhas anteriores, a questão da instituição escolar. Isto é, assumir que o sentido da mesma está deteriorado. Sem dúvida, devemos nos posicionar diante do contexto atual, como contexto transicional: Modernidade, e isto que ela não é, esta é a questão que devemos assumir como educadores neste tempo em que vivemos. Porque na realidade, náo se trata de uma época de grandes mudanças, mas sim de uma mudança de época, de onde o velho se derruba e o novo não nasceu, o qual tem a existência inserida em um mal-estar e uma incerteza.

E isso consiste em habitarmos a sociedade, a escola e as instituiçóes, pois somos partícipes ou meramente espectadores deste tempo de mudança social, política e econômica. Por essa razão, é muito difícil responder ao sentido atual da escola, porque o sentido se desconfigurou.

A transmissão da cultura, como decisão política, começa a fraquejar quando se percebe que o formato escolar moderno está sendo consumido. Sobre isso, Guillermina Tiramonti (2003) pergunta se pode falar de sistema educativo na atualidade. O mesmo requer certas características: significado social dos processos de transmissão cultural e certa correlação entre a cultura escolar e a cultura social. O dicionário Larrouse (2005) oferece entre várias aceitaçóes, que é a que consideramos pertinente aos efeitos da proposta: sentido, finalidade ou razão de ser; este texto absurdo carece de sentido. Desse modo, teremos como desafio analisar a escola como um espaço cuja finalidade ou razão 
de ser na atualidade, está muito certo de se ter um discurso absurdo. Se a escola está nessas condiçôes nos permitimos fazer a pergunta: qual é a sua finalidade?

Tiramonti (2004, p . 11) observa que "[...] é claro que nós habitamos um espaço de colapso de certezas conceituais, identidade e mitos da nação e das instituiçôes com as quais teceu o tecido da sociedade moderna".

Propomos um olhar diferenciado, uma perspectiva de encontrar, olhar, sentir as rajadas de sentido, que, em princípio, não nos levará a razão de nossa definição levantada em um dicionário, mas explosóes simultâneas de significados, em conjunto e debate como formas e com a paciência que não é peculiar à cultura da época corrente instantânea, onde os educadores podem pesquisar e citar essas explosôes, e provavelmente posicionar-se para nós como ares novos.

E é nesse ponto que a gestão da educação deve ocupar um papel central na nossa América Latina. Os professores como intelectuais ocupam qual papel na reconstruçáa do colapso das instituiçóes de ensino? Que contribuição podemos tirar da gestão, quando percebemos que as instituiçôes educativas não estão mais exercendo seu papel na formação do ser humano? Ou neoliberalismo será o agente responsável de dar novos significados para a escola, tornando a um dispositivo reprodutor de sua hegemonia?

Aqui nos referimos aos fenômenos educacionais e, particularmente, a maneira em que se vive, em que habitamos hoje a instituição escolar enquanto responsável pela transmissão cultural de transferência de conhecimento. Sendo ssim, faz-se necessário realizar uma gestão de projetos educacionais e repensar o caminho da escola.

Para isso, é necessário começar a restituir, a partir da gestão educacional, a pensar a gestão educacional como restauradora, capaz de gerar explosóes de sentido, dado que, na confusáo em que a escola vive hoje a gestão educacional neoliberal, muitas vezes tem se apresentado como a panaceia para as dificuldades. Esta restituição da escola traz inerente em si a ideia de invençáo.

A restituiçáo da escola tem que dar espaço para as rajadas de significado, que se tornam capazes de gerar. Devemos pensar em construir uma nova escola. Assim, há uma grande diferença entre a reinvenção da gestão e um compromisso com a invenção de um pensamento de gestão da educação na América Latina.

A gestáo de energia está ligada ao conhecimento sensível. Onde está a escola? Gestão implica em conhecimento, mas não um mero conhecimento técnico, mas sim um conhecimento da situação em que se intervém: a escuta atenta, a proposta de criar condiçôes para pensar, redesenhando o caminho. Aqui, novamente temos abordado uma definição que achamos que pode ser de interesse em nossas atitudes, e que não pertencem aos países centrais. 
É possível criar condiçốes para que algo tenha poder, para que alguns se mobilizem diante dessa realidade que se mostra em relação à escola. A gestão educacional tem, então, um caráter triplo:

¿ Restituiçãoo - geraçáo de sentido;

$¿$ Condiçôes - pensamento de possibilidade e realidade;

$¿$ Power - pensando que transforma.

Gestão ocorre na situação concreta da escola, portanto, não se liberam os obstáculos e a realidade, ou seja, gerenciar é fazer que se produza a ocorrência de movimento de começar a permitir a possibilidade de mudanças, em oposição à completude, à harmonia do "tudo está bem". Provavelmente isso vai doer um pouco, mas temos que enfrentá-lo nesse momento de transiçấo. Em busca de um norte podemos assumir as palavras de Nietzsche (2003, p. 189) para iniciar a gestáo da escola na América Latina:

Saímos do continente, nós embarcamos.

Que deixamos para trás a ponte, rompemos laços com o continente.

Ehh, Barquita ...! Tenha Cuidado! Ao seu lado está o oceano, nem

sempre brando, e as vezes parece de sede e de outro, e é amigável. Mas chegará o momento em que verás que é infinito.

Em vez de negar o que é apresentado hoje como uma escola, a escola deve começar a pensar como fundar nova escola, com essas crianças e jovens, sem perder a função, mas encorajando-nos a abandonar a terra onde respostas claras não farão nada que obscurecem a possibilidade de gerar, inventar, de gestionar para dar lugar, gestionar para fazer da escola uma verdadeira experiência educacional.

Gestão envolve a criação de condições. O trabalho de gestão vai além de se listar pontos fortes e fracos, é um esforço persistente para uma leitura crítica de mundo, para mudar o que passa de uma forma injusta. Paulo Freire (1996) apoiou a esperança radical na possibilidade de sempre transformar o mundo existente, onde o objetivo maior se tornou em participar da luta pela defesa da igualdade de oportunidades. Assim, e considerando a realidade estranha, a gestão institucional é a possibilidade de democratização e de análise crítica da realidade social.

A gestão efetiva é aquela que rompe com o que se vem fazendo e se desprende, ou o que se intenta reconstruir, e, às vezes, tudo isso junto ou um de cada vez, porque trabalhar a escola e a gestão da escola não tem que ver com o ato isolado e recortado, nem com uma sequência de passos de uma receita técnica, é muito mais que isso. Gestão implica em estar rompendo com o que foi feito, porque trabalhar na escola, na gestão da 
escola não tem relação com um ato puro e aparado, nem uma sequência passo-receita, mas sim em escutar a realidade.

A palavra em si não quer dizer nada. A palavra que oculta e a que desvela. A palavra dada. Como possibilidade de pensar, o sentido que foi dito ao outro nos coloca em situação de pensar sobre nossa experiência. A palavra que aparece espontaneamente ou a aquela que nos é provocada. Daí a ideia de gestão reconstitutiva, a palavra que penetra no sentido, que pergunta para descobrir o que é diferente e vai para além da repetição, que intenta escutar a palavra que diz coisas distintas, uma de cada vez.

A escuta é o que avança sobre a compreensão e, para tanto, desnaturaliza o que parecer ser obvio. Escutar a gestão tem a ver com atender e suspender o juízo e o prejuízo para apreender o que o outro sente, vive, precisa. Assim, escutar tem relaçáo com o reconhecer-se como parte da situação de escuta, muito mais do que ouvinte, é avançar no entendimento e, portanto, parece óbvio desnaturado.

A gestão envolve lidar e suspender o julgamento e o preconceito de ir para o que o outro sente, vive. Gestão sem os outros é impossível. Devemos, sim, ver a todos, encontrar a todos, e isso não é pouco, e nem tão fácil. As situaçôes de alta dificuldade e de profundo sofrimento promovem saídas que renegam, saiam de circulação, imaginam açóes mágicas para transformar o outro segundo nosso desejo. Gestão com outros implica um posicionamento, um olhar que se reconhece em sua trajetória, em sua diferença. Está aí. Este é o segredo!

Trabalhar na gestão tem a ver com instalar um questionamento que permita vislumbrar algo novo, náo pelo original, por tratar-se de uma resposta diferente aos eixos habituais.

Voltar o olhar ao que é conhecido e encontrar ruas, marcas, legados, tradiçóes: advertir sobre os múltiplos olhares, os diversos espectadores e protagonistas, inscreverse na transmissão e posicionar-se como pensador de si próprio e do de outros: fazer uma reflexão sobre a reflexão da ação, sem que seja um tempo roubado àquele que supostamente deve fazer, senáo um ato que mobiliza a inteligência e o pensamento.

\section{Notas}

${ }^{1}$ Parte deste texto foi socializada por Elson Rogério Bastos Pereira e Susana da Silva Pires de Liz, que fazem parte do Grupo de Pesquisa de Educação Superior da UNIPLAC, do qual a autora foi coordenadora, no X ANPED Sul, realizada em outubro de 2014, em Florianópolis. Disponível em: <http://xanpedsul.faed.udesc.br/arq_pdf/2105-0.pdf>.

${ }^{2}$ Segundo Gentili (1998, p. 16), “Uma retórica e um núcleo de propostas comuns orienta as políticas de ajuste implementadas na esfera educacional, o qual não expressa outra coisa senão a particularidade que assume o Consenso de Washington numa área prioritária da reforma social impulsionada pelo neoliberalismo. De fato podemos dizer 
que esse conjunto de discursos, ideias e propostas sintetizam o que poderia ser definido como a forma neoliberal de pensar e delinear a reforma educacional na América Latina dos anos noventa".

${ }^{3} \mathrm{O}$ Acuerdo General sobre el Comercio de Servicios (GATS) é um dos acordos de maior alcance da Organização Mundial de Comércio (OMC). Seu propósito é liberar progressivamente o "comercio de servicios" entre os membros da OMC. O GATS entrou em vigor em janeiro de 1995, mas as negociaçóes começaram oficialmente em 2000. Em março de 2001, o Conselho de Comercio de Serviços estabeleceu as Diretrices e procedimientos para as negociaçóes na Declaración de la Conferencia Ministerial de Doha (novembro de 2001). que respaldou o trabalho realizado, reafirmando as diretrizes e procedimentos para as negociaçóes e estabeleceu o prazo para a conclusão das negociaçóes em $1^{\circ}$ de janeiro de 2005 . Ante o novo processo pósneoliberal onde os Estados Latinoamericanos começam a ter um rol de maior presença, ao menos o que diz respeito a década de 1990, observando na nossa regiáo as diversas estratégias, documentos ou leis, no qual os Estados têm tomado uma postura de oposição ao conceber a educação como um serviço no sentido proposto pela OMC.

\section{REFERÊNCIAS}

ALVES, Ana Elizabeth Santos. Qualificação e Trabalho no Capitalismo. Revista da FAEEBA: Educação e Contemporaneidade, Salvador, v. 15, n. 26, p. 45-56, jul./dez., 2006.

ARGENTINA. Ley no 24.195, de 14 de abril de 1993. Ley Federal de Educación. Diario Oficial, Buenos Aires, 29 abr. 1993.

ARGENTINA. Ley no 26.206, de 14 de diciembre de 2006. Ley de Educación Nacional. Diario Oficial, Buenos Aires, 27 dic. 1993.

BALL, Stephen J. Grandes políticas, un mundo pequeno: introducción a una perspectiva internacional en las políticas educativas. In: NARODOWSKI, Mariano; NORES, Milagros; ANDRADA, Myrian. Nuevas tendencias en politicas educativas: estado, mercado y escuela. Buenos Aires: Granica, 2002. p. 103-128.

BELLO, María Eugenia. Reformas y políticas educativas en América Latina. Acción Pedagógica, Mérida, v. 10, n. 1, 2001.

BLASCO, Carlos Miñana; RODRÍGUEZ, José Gregorio. La educación en el contexto neoliberal. In: BOTERO, Dário I. Restrepo (Ed.). Neoliberal: crítica y alternativas. Bogotá: Universidad Nacional de Colombia, 2003. p. 285-321.

BOLIVIA. Ley no 1.565, de 7 de julio de 1994. Decreta Ley de Reforma Educativa. Diario Oficial, La Paz, jul. 1994. 
BRASIL. Lei no 9.394, de 20 de dezembro de 1996. Estabelece as diretrizes e bases da educação nacional. Diário Oficial da Uniāo, Brasília, DF, 20 dez. 1996.

CASASSUS, Juan. Problemas de la gestión educativa en América Latina. Chile: UNESCO, 2000.

CARNOY, Martin. ¿Están funcionando las reformas educativas en Latinoamérica? Nuevas perspectivas. Washington: BID, 2002.

CHILE. Ministerio de Educación. Ley n ${ }^{\circ}$ 18.962, de 7 de marzo de 1990. Ley Orgánica Constitucional de Enseñanza. Diario Oficial, Valparaíso, 10 mar. 1990.

CHILE. Ministerio de Educación. Ley n 19.876, de 7 de maio de 2003. Reforma constitucional que establece la obligatoriedad y gratuidad de la educación media. Diario Oficial, Valparaíso, 22 maio 1990.

CORAGGIO, José Luis. Desarrollo humano y política educativa en ca Ciudad Latinoamericana. In: SEMINARIO INTERNACIONAL EDUCACIÓN POPULAR Y UNIVERSIDAD, 3., 1994, João Pessoa. Anais... João Pessoa: UFPB, 1994.

CONTRERAS, José. ¿Autonomía por decreto? Education Policy Analysis Archives, Tucson, AZ, v. 7, n. 17, abr. 1999.

ECUADOR. Ley Orgánica De Educación Intercultural, de 30 de marzo de 2011. Registro Oficial, Quito, 31 mar 2011.

FERREIRA, Naura Syria Carapeto (Org.). Formação Continuada e Gestão da Educação. São Paulo: Cortez, 2003a.

FERREIRA, Naura Syria Carapeto. A gestão da educação na sociedade mundializada: por uma nova cidadania. Rio de Janeiro: DP\&A, 2003b.

FREIRE, Paulo. Pedagogia da Autonomia: saberes necessários à prática educativa. Sáo Paulo: Paz e Terra, 1996.

GARDUÑO, José. La administración y gestión educativa: algunas lecciones que nos deja su evolución en los Estados Unidos y México. Revista Interamericana de Educación de Adultos, Pátzcuaro, ano 26, n. 1, 2004.

GARRETÓN, Manuel. Latinoamérica un espacio cultural en un mundo globalizado. Bogotá: Convenio Andrés Bello, 1999. 
GENTILI, Pablo. A falsificação do consenso: simulacro e imposição na reforma educacional do neoliberalismo. Rio de Janeiro: Vozes, 1998.

GENTILI, Pablo. Desencanto e utopia: a educação no labirinto dos novos tempos. Petrópolis, RJ: Vozes, 2008.

GINSBURG, Mark B. (Ed.). Understanding educational reform in global contexto: Economy, Ideology and the State. Nova York: Garland. 1991.

GINSBURG, Mark et al. National and world system explanations of educational reform. Comparative Education Review, v. 34, n. 4, p. 474-499, 1990.

GRAMSCI, Antônio. Obras Escolhidas. Tradução de Manuel Cruz e Nei Rocha da Cunha. São Paulo: Martins Fontes, 1978.

KAES, René. Transmisión de la vida psíquica entre generaciones. Buenos Aires: Amorrortu. 1996.

LÜCK, Heloísa. Concep̧̧ôes e processos democráticos de gestão educacional. Petrópolis, RJ: Vozes, 2006.

MÈSZÁROS, István. Educação para além do Capital. Tradução de Isa Tavares. São Paulo: Boitempo, 2005.

MEXICO. Ley General De Educación. Diario Oficial de la Federación, Ciudad de México, 13 jul. 1993.

MEXICO. Secretaria De Educacion Publica. Decreto por el que se reforman diversas disposiciones de la Ley General de Educación, en materia de educación preescolar. Diario Oficial de la Federación, Ciudad de México, 10 dic. 2004. Disponível em: <http://www.diputados.gob.mx/LeyesBiblio/ref/lge/LGE_ref05_10dic04.pdf>. MONLEVADE, João; SILVA, Maria Abadia da. Quem Manda na Educação no Brasil. Brasília, DF: Editora do Sindicato, 2000.

PERU. Ley n 28.044, de 2003. Ley General Educación, Lima, 2003.

NIETZSCHE, Friedrich. Asi Hablo Zaratustra: un libro para todos y para nadie. Madrid: Alianza, 2003.

SAVIANI. Dermeval. Escola e Democracia. 31. ed. São Paulo: Autores Associados, 1997. 
SCHÖN, Donald A. Formar professores como profissionais reflexivos. In: NÓVOA, António (Coord.). Os professores e sua formação. Lisboa: Dom Quixote, 1992.

SVAMPA, Maristella. La sociedad excluyente: la Argentina bajo el signo del neoliberalismo. Buenos Aires: Taurus, 2005.

TIRAMONTI, Guillermina (Org..). La trama de la desigualdad educativa. Buenos Aires: Manantial, 2004. 


\section{Education and school manage- ment in Latin America: history, challenges and opportunities}

\begin{abstract}
This article intends to think the school as a place of tolerance and respect that fosters the development of a democratic culture, so that its operation encourages the participation of all in decision making processes. This seems to be utopian and not part of the political will of the leaders of the globalized and - especially capitalist world. The work performed in school management, in most cases, loses the sense of space of exchanges, of social construction and relationship, and is seen only as a factor of economic emancipation and currency exchange, which is illusory because the compensation offered according to the market no long meets the real needs. This way, our goal is to discuss the school management before a historical context in Latin America, which is dictated by a neoliberal state that does not value the school education and that understands labor as sale of productive force for a salary at the end of the month and not as production of human existence.
\end{abstract}

Keywords: School Management in Latin America. Education and Management. School and Management in Latin America.

\section{La educación y la gestión de las escuelas en América Latina: historia, retos y posibilidades}

\section{Resumen}

Este artículo se propone pensar la escuela como un lugar de tolerancia y de respeto que propicie el desarrollo de una cultura democrática, por lo que su funcionamiento anima a la participación de todos en la toma de decisiones. Esto parece ser una utopía y no forma parte de la voluntad política de los líderes del mundo globalizado y sobre todo capitalista. En el trabajo de gestión en la escuela, la mayoría de las veces, se pierde el sentido del espacio de intercambio, la construcción y las relaciones sociales, y es visto sólo como un factor de emancipación económica, el comercio de divisas, que es ilusorio, porque la remuneración ofrecida a partir de la lógica del mercado no atiende desde hace mucho tiempo las necesidades reales. Por lo tanto, el objetivo es discutir la dirección [gestión] de la escuela en un contexto histórico en América Latina, dictada por un Estado neoliberal que no valora la educación escolar y que entiende el trabajo como la venta de la fuerza productiva para un sueldo a fin de mes, y no como una producción de la existencia humana.

Palabras claves: Gestión Escolar en América Latina. Educación y Gestión. Escuela y Gestión en América Latina. 


\section{Maria de Lourdes Pinto de Almeida}

E-mail:malu04@gmail.com

\section{Cesar Gerónimo Tello}

E-mail: cesargeronimotello@yahoo.com.br

Enviado em: 1/2/2012 Aprovado em: 21/3/2014 